\title{
A RANDOMISED DOUBLE BLIND CLINICAL TRIAL COMPARING 0.75\% ISOBARIC ROPIVACAINE WITH 0.50\% ROPIVACAINE WITH CLONIDINE COMBINATION IN SUBARACHNOID BLOCK FOR TRANSURETHRAL RESECTION OF PROSTATE
}

\author{
Arif Sohaib' ${ }^{1}$ Shraddha Naik², V. K. Dhulkhed ${ }^{3}$ Naseema Kanase ${ }^{4}$, Harshali Patil 5 \\ ${ }^{1}$ Resident, Department of Anaesthesiology, KIMSDU, Karad. \\ ${ }^{2}$ Assistant Professor, Department of Anaesthesiology, KIMSDU, Karad. \\ 3 Professor and HOD, Department of Anaesthesiology, KIMSDU, Karad. \\ 4 Professor, Department of Anaesthesiology, KIMSDU, Karad. \\ ${ }_{5}^{5}$ enior Resident, Department of Anaesthesiology, KIMSDU, Karad.
}

\section{ABSTRACT}

\section{BACKGROUND}

The aim of this study was to evaluate the association of a small dose of intrathecal ropivacaine with small doses of intrathecal clonidine for TURP surgery.

\section{METHODS}

Eighty patients, classified as American Society of Anaesthesiologists, physical status I and II scheduled for TURP were studied. Patients were randomly assigned to receive $4 \mathrm{~mL}$ of one of the following double blinded isobaric intrathecal solutions: $4 \mathrm{~mL}$ of $0.75 \%$ ropivacaine (Group I; $\mathrm{n}=40$ ) and $3.5 \mathrm{~mL} 0.50 \%$ ropivacaine- $30 \mathrm{mcg}$ clonidine combination with $0.3 \mathrm{~mL}$ sterile normal saline (Group II; $\mathrm{n}=40$ ). The level and duration of sensory anaesthesia were recorded along with the intensity and duration of motor block and duration of postoperative analgesia and the need of opioid (tramadol) postoperatively.

\section{RESULTS}

Ropivacaine and ropivacaine-clonidine combination had a similar onset, but the duration of sensory block was prolonged in ropivacaine-clonidine combination $(120.5 \pm 8.55 \mathrm{~min})$ in comparison to plain ropivacaine $(108.4 \pm 12.55 \mathrm{~min})$. The duration of motor block was comparable in both groups. Postoperative analgesia was prolonged in ropivacaine-clonidine group and the need for postoperative opioid (Tramadol) was lesser in this group compared to plain ropivacaine group.

\section{CONCLUSION}

Addition of low-dose clonidine to isobaric ropivacaine showed longer duration of sensory block and longer postoperative analgesia. The onset of sensory block and onset and duration of motor block were similar without significant haemodynamic changes.

\section{KEYWORDS}

Ropivacaine, Clonidine, TURP, Prostate.

HOW TO CITE THIS ARTICLE: Sohaib A, Naik S, Dhulkhed VK, et al. A randomised double blind clinical trial comparing 0.75\% isobaric ropivacaine with $0.50 \%$ ropivacaine with clonidine combination in subarachnoid block for transurethral resection of prostate. J. Evolution Med. Dent. Sci. 2016;5(67):4779-4782, DOI: 10.14260/jemds/2016/1089

\section{INTRODUCTION}

Relief of pain during operation is one of the mainstays of balanced anaesthesia. So, any experience acquired in this field should be extended to the postoperative period also. Postoperative pain relief is a growing concern for an anaesthesiologist as an uneventful postoperative period makes surgery a comfortable proposition for surgical patients. ${ }^{1}$

Spinal anaesthesia is one of the most popular techniques for both elective and emergency surgical procedures. ${ }^{2}$ The advantages of an awake patient, simple to perform, offers rapid onset of action, minimal drug cost, relatively less side effects, and rapid patient turnover has made this the choice of many surgical procedures. ${ }^{3}$

Financial or Other, Competing Interest: None.

Submission 07-04-2016, Peer Review 02-07-2016,

Acceptance 07-07-2016, Published 20-08-2016.

Corresponding Author:

Dr. Arif Sohaib,

\#A-201, Fakhruddin Apartments,

Plot-18, Sector 10, Dwarka,

New Delhi-110075.

E-mail:drarifsohaib@gmail.com

DOI: $10.14260 /$ jemds/2016/1089
Bupivacaine has been in clinical use since $1963 . .^{4}$ It has been classified as an agent of high anaesthetic potency and long duration of action, which like all amide anaesthetics has been associated with cardiotoxicity when used in the high concentration or when accidentally it is administered intravascularly.

Ropivacaine, which is structurally similar to bupivacaine has been introduced since 1996. It produces less motor blockade and is of shorter duration than bupivacaine.5,6 Ropivacaine in equipotent doses has been shown to be virtually indistinguishable from bupivacaine for clinical anaesthesia without any obvious disadvantage. ${ }^{7}$

Intrathecal clonidine is being extensively evaluated as an alternative to neuraxial opioids for control of pain and has proven to be a potent analgesic free of at least some of the opioid-related side effects. ${ }^{8}$ It prolongs the necessary blockade ${ }^{9,10}$ and reduces the amount or concentration of local anaesthetic required to produce postoperative analgesia. ${ }^{11,12}$

This present study was designed to evaluate the clinical efficacy and safety of $0.75 \%$ isobaric ropivacaine alone and $0.50 \%$ isobaric ropivacaine with 30 mcg clonidine combination in BPH patients undergoing TURP under subarachnoid block. 


\section{MATERIALS AND METHODS}

This prospective, randomized, double blind clinical study was conducted on 80 male adult patients of physical status ASA grade I-II, aged 46-75 years scheduled for TURP under subarachnoid block from August 2013 to August 2015. This study was carried out at Krishna Institute of Medical Sciences Deemed University, Karad. After approval of Institutional Ethical Committee and written informed consent, all patients were subjected to pre-anaesthetic assessment. Patients with history of cardiovascular disease, allergy to amide local anaesthetic, alcohol or drug abuse, known neurological disease, known autonomic neuropathy, infection at site of lumbar puncture, and failure of spinal anaesthesia were excluded from the study. Before enrolment for the study, patients were explained on the method of sensory and motor assessments.

The patients were randomized according to closed envelope technique into two treatment groups of 40 each to receive either an intrathecal injection of $4 \mathrm{~mL}$ of $0.75 \%$ isobaric ropivacaine (Group I, $n=40$ ) or $3.5 \mathrm{~mL}$ of $0.75 \%$ isobaric ropivacaine with $30 \mathrm{mcg}$ clonidine plus $0.3 \mathrm{cc}$ of sterile normal saline (Group II, $n=40$ ). They were preloaded with lactated Ringer $10 \mathrm{~mL} / \mathrm{kg}$ before the initiation of the subarachnoid block and standard monitors for heart rate, continuous ECG (lead II), continuous pulse oximetry, and noninvasive Systemic Blood Pressure (SBP) were attached. The subarachnoid puncture was performed aseptically in the sitting position with a 25 G Quincke needle by midline approach at the L2-3 or L3-4 interspace and one of the study drug was given over $30 \mathrm{~s}$ according to group allocation. The direction of the needle aperture was cranial during injection. Immediately after intrathecal injection, patients were laid supine.

Haemodynamic parameters were monitored at baseline after drug injection for every 2 mins for first 10 mins, then every 15 mins for next 40 mins, and 20 mins thereafter till end of the transfer of patient.

The onset and duration of sensory blockade with maximal cephalad spread, the onset, intensity, and duration of motor blockade were recorded at 1 and 2 min followed by at $2 \mathrm{~min}$ intervals till the surgical anaesthesia was achieved at the dermatome level T10. The segmental level of sensory block to pinprick was evaluated bilaterally along the mid clavicular line by using a short bevelled 27-gauge needle.

The motor block of both legs was assessed using the modified Bromage scale (Score 1-complete block (unable to move feet or knees), 2-Almost complete block (Able to move feet only), 3-Partial block (just able to move knees),

4-Detectable weakness of hip flexion while supine (Full flexion of knees), 5-No detectable weakness of hip flexion while supine, 6-Able to perform partial knee bend. The surgical anaesthesia was considered effective when at least the T10 dermatome was anaesthetised. After adequate spinal block has been achieved, the time from the end of intrathecal injection to readiness for surgery was noted. Then, the patient was positioned in the lithotomy position and surgery started.

Time to first request for postoperative analgesia - defined as the period from spinal injection to the administration of first rescue analgesic for pain in the postoperative period was noted. Total opioid (Tramadol) consumption in first $24 \mathrm{hrs}$. following surgery was also noted.

Criteria for tachycardia, bradycardia, hypotension, and hypertension were any increase or decrease more than $20 \%$ from the baseline. The hypotension (SBP $<90 \mathrm{mmHg}$ ) was treated with intravenous boluses of phenylephrine $25 \mathrm{mcg}$ and additional Ringer lactate solution and bradycardia (Heart rate $<50 \mathrm{~b} / \mathrm{m}$ ) with intravenous atropine. Respiratory depression was defined when a respiratory rate is less than 8 breaths/min or oxygen saturation less than $90 \%$ on air. All patients were catheterised after surgery.

\section{STATISTICAL ANALYSIS}

The sample size was based on initial pilot study, which indicated that approximately 26 patients should be included in each group in order to detect a $30 \mathrm{~min}$ difference in the mean duration of motor blockade between the groups for type 1 error of 0.01 and power of $90 \%$. However, we have used a total sample size of 80 patients. Statistical analysis was done for comparing observed data by using Student's t test, chi-square test, and Mann-Whitney $\mathrm{U}$ test, and $\mathrm{P}$ value of $<0.05$ was considered statistically significant.

\section{RESULTS}

\begin{tabular}{|c|c|c|c|c|c|c|c|c|}
\hline Group & N & Age & Group & N & Height & Group & N & Weight \\
\hline I & 40 & $64.67 \pm 8.215$ & I & 40 & $168.94 \pm 10.725$ & I & 40 & $65.78 \pm 4.647$ \\
\hline II & 40 & $65.14 \pm 7.42$ & II & 40 & $170.52 \pm 9.988$ & II & 40 & $64.24 \pm 6.54$ \\
\hline \multicolumn{8}{|c|}{ Table 1: Demographic Parameters } \\
\hline
\end{tabular}

Eighty elderly consented patients were randomized to the two treatment groups of 40 patients each. The demographic data were similar between the groups for age, weight, height, ASA classification, as well as duration of surgery.

\begin{tabular}{|c|c|c|c|c|c|}
\hline Group & $\begin{array}{c}\text { Time to onset (Min) } \\
\text { at T10 } \\
\text { (Mean } \pm \text { S.D) }\end{array}$ & $\begin{array}{c}\text { Maximal } \\
\text { sensory level } \\
\text { (Mean } \\
\pm \text { S.D) }\end{array}$ & $\begin{array}{c}\text { Time (Min) taken to } \\
\text { achieve maximal } \\
\text { Sensory Block } \\
\text { (Mean } \pm \text { S.D) }\end{array}$ & $\begin{array}{c}\text { Duration (Min) } \\
\text { of Sensory block at } \\
\text { T10 (Mean } \pm \text { S.D) }\end{array}$ & $\begin{array}{c}\text { Duration (Min) of } \\
\text { Sensory Block till } \\
\text { regression } \\
\text { (Mean } \pm \text { S.D) }\end{array}$ \\
\hline I & $3.57 \pm 1.37$ & T6 \pm 2 & $7.50 \pm 2.02$ & $108.4 \pm 12.55$ & $205 \pm 26.31$ \\
\hline II & $4.12 \pm 1.38$ & T8 \pm 2 & $8.25 \pm 2.33$ & $120.5 \pm 8.55$ & $255.5 \pm 65.47$ \\
\hline P Value & 0.07 & \multicolumn{3}{r|}{ Table 2: Sensory Block-Onset, Level, Duration, and Regression } \\
\hline \multicolumn{7}{r}{}
\end{tabular}


Table 2, shows no significant difference in the median time of onset of sensory blockade at the T10 dermatome, which was $3.57 \pm 1.37 \mathrm{~min}$ in the Group I and $4.12 \pm 0.07 \mathrm{~min}$ in Group II (P Value $=0.07$ ) and the time taken to achieve maximum sensory block, which was $7.50 \pm 2.02 \mathrm{~min}$ in Group I and $8.25 \pm 2.33 \mathrm{~min}$ in Group II (P Value=0.18). The adequate level of sensory analgesia was achieved in all patients before surgery. Significant difference was seen in the duration of sensory block at T10, which was $108.4 \pm 12.55 \mathrm{~min}$ in Group I and $120.5 \pm 8.55 \mathrm{~min}$ in Group II statistically significant (P Value $=0.04$ ). The median duration of sensory blockade till complete regression was $205 \pm 26.31$ min in Group I and $255.5 \pm 65.47$ in Group II, which was statistically significant (P Value=0.01).

\begin{tabular}{|c|c|c|}
\hline Group & $\begin{array}{c}\text { Time (Min) taken for } \\
\text { complete block } \\
\text { (Mean } \pm \text { S.D) }\end{array}$ & $\begin{array}{c}\text { Duration (Min) of } \\
\text { Block (Mean } \pm \text { S.D) }\end{array}$ \\
\hline $\mathrm{I}(\mathrm{R})$ & $12.55 \pm 2.39$ & $173.50 \pm 25.57$ \\
\hline $\mathrm{II}(\mathrm{RC})$ & $13.57 \pm 2.49$ & $176 \pm 53.31$ \\
\hline P Value & 0.09 & 0.79 \\
\hline \multicolumn{3}{|c|}{ Table 3: Motor Block-Onset, Duration } \\
\hline
\end{tabular}

The onset and duration of motor block was comparable in both the groups and was not statistically significant.

\begin{tabular}{|c|c|c|c|c|c|}
\hline Group & Heart Rate & S.B.P & D.B.P. & Mean B.P. & Sp02 \\
\hline I & $68.45 \pm 3.24$ & $122.64 \pm 6.78$ & $78.47 \pm 2.44$ & $89.86 \pm 5.78$ & $99.10 \pm 0.86$ \\
\hline II & $70.05 \pm 2.89$ & $114.14 \pm 5.21$ & $67.21 \pm 3.65$ & $82.85 \pm 4.65$ & $99.04 \pm 0.94$ \\
\hline \multicolumn{7}{|c|}{ Table 4: Haemodynamic Parameters } \\
\hline
\end{tabular}

Haemodynamic changes of systolic blood pressure and heart rate of both groups are shown in Table 3. The heart rate, systolic, diastolic, and mean blood pressure, and oxygen saturation was comparable in both the groups throughout the surgery with no statistical difference.

\begin{tabular}{|c|c|c|}
\hline Group & $\begin{array}{c}\text { Time (Min) to first } \\
\text { request for } \\
\text { postoperative } \\
\text { analgesia } \\
\text { (Mean } \pm \text { S.D) }\end{array}$ & $\begin{array}{c}\text { Total opioid (Tramadol) } \\
\text { consumption in } \\
\text { milligrams in first 24 hrs. } \\
\text { following surgery } \\
\text { (Mean } \pm \text { S.D) }\end{array}$ \\
\hline I(R) & $336 \pm 76.18$ & $96.25 \pm 39.85$ \\
\hline II (RC) & $403.45 \pm 89.03$ & $77.50 \pm 39.14$ \\
\hline P value & 0.005 & 0.03 \\
\hline \multicolumn{2}{|c|}{ Table 5: Requirement of } \\
\multicolumn{2}{|c|}{ Postoperative Analgesia } \\
\hline
\end{tabular}

Table 5 shows that the duration of postoperative analgesia was prolonged in Group 2 as compared to Group 1 ( $P$ value $=0.005)$, which was statistically significant. The total opioid (Tramadol) consumption (mg) in first 24 hours following surgery was statistically significant ( $P$ Value $=0.03$ ) for Group I $(96.25 \pm 39.85)$ in comparison to group II

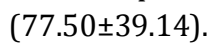

The incidence of adverse effects of pruritus, nausea, vomiting, and shivering was comparable between two groups. No patients complained of any other neurological symptoms at the postoperative visit.

\section{DISCUSSION}

Ropivacaine is a potent local anaesthetic with a long duration of action. The amount of local anaesthetic usually used for spinal anaesthesia is larger in relation to the minimum concentration required to block the various types of nerve fibers. Using smaller doses of ropivacaine will reduce the duration of spinal block, but sometimes a smaller number of dermatomes are blocked. Intrathecal clonidine increases the duration of sensory block as well as postoperative pain relief.

The present study was designed to compare the anaesthetic efficacy and safety of intrathecal $0.75 \%$ isobaric ropivacaine alone or $0.50 \%$ isobaric ropivacaine with $30 \mathrm{mcg}$ clonidine combination for transurethral resection of prostate in elderly patients. The study showed that intrathecal administration of ropivacaine alone or with intrathecal clonidine has provided effective surgical anaesthesia for TURP surgery with cardiovascular stability. Intrathecal ropivacaine with clonidine have no changed effect on the onset of sensory analgesia, but has improved the quality and duration of the sensory blockade without compromising early mobilization and discharge.

Ogun $\mathrm{C}$ et al. ${ }^{13}$ stated in their study that the time of onset of ropivacaine in comparison to ropivacaine-clonidine combination was comparable. Kallio $\mathrm{H}$ et al. ${ }^{14}$ stated that the time for complete T10 blockade was faster in hyperbaric ropivacaine in comparison to plain ropivacaine.

In our study, duration of sensory block till regression was prolonged in group II. A similar result has been reported by Kock D et al. ${ }^{15}$ who conducted a dose-response study investigating the effects of adding clonidine $(15,45$, or $75 \mu \mathrm{g})$ to a fixed dose of isobaric spinal ropivacaine $(8 \mathrm{mg})$ for ambulatory knee arthroscopy.

In our present study, time to first request for postoperative analgesia (Min) was considerably prolonged in group II. Ogun $\mathrm{C}$ et $\mathrm{al}^{13}$ found similar results in their study where plain ropivacaine was compared to ropivacaine-clonidine combination in patients undergoing caesarean section.

There was no significant difference in adverse effect profile of both the groups.

\section{CONCLUSION}

The addition of clonidine $30 \mathrm{mcg}$ to $0.50 \%$ isobaric ropivacaine when compared to $0.75 \%$ isobaric ropivacaine alone in subarachnoid block for transurethral resection of prostate showed longer duration of sensory block and longer postoperative analgesia. The onset of sensory block, onset and duration of motor block were similar without significant haemodynamic changes.

\section{REFERENCES}

1. Vaswani RK, Raiger LK, Purohit R, et al. The effect of intrathecal midazolam on postoperative pain relief in orthopaedic surgery. Hospital Today 2002;7(4):150-3.

2. Dureja GP, Jayalaxmi TS. Colloid preloading before spinal and epidural anaesthesia. Hospital Today 2000;5(11):601-3.

3. Paul GB, Bruce FC. Clinical Anaesthesia. Vol 6, Lippincott, Williams and Wilkins 2006:700-6. 
4. Savarese J, Covino B. Basic and clinical pharmacology of local anaesthetic drugs. In: Anaesthesia, Miller RD. New York: Churchill Livingston, New York, Edinburgh, London, Melbourne 1986;2(2):986-7, 985-1013.

5. Scott, Lee A, Fagan D. Acute toxicity of ropivacaine compared with that of bupivacaine. Anaesth Analg 1995;69:563-9.

6. Markham F. Ropivacaine a review of its pharmacology and therapeutic use in regional anaesthesia. Br J Anaesth 1996;76:300-7.

7. Atanassoff. Ropivacaine in equipotent dose shown to be virtually indistinguishable from bupivacaine for clinical anaesthesia without any obvious advantages. Acta Anaesth 2003;54:426-32.

8. Eisenach JC. Overview: first international symposium on $\alpha-2$ adrenergic mechanisms of spinal anaesthesia. Reg Anaesth 1993;18(4):207-12.

9. Dobrydnjov I, Samarutel J. Enhancement of intrathecal lidocaine by addition of local and systemic clonidine. Acta Anaesthesiol Scand 1999;43(5):556-62.

10. Niemi L. Effects of intrathecal clonidine on duration of bupivacaine spinal anaesthesia, haemodynamics and postoperative analgesia in patients undergoing knee arthroscopy. Acta Anaesthesiol Scand 1994;38(7):724-8.
11. Dobrydnjov I, Axelsson K, Samarutel J, et al. Postoperative pain relief following intrathecal bupivacaine combined with intrathecal or oral clonidine. Acta Anaesthesiol Scand 2002;46(7):806-14.

12. Park J, Forrest J, Kolesar R, et al. Oral clonidine reduces postoperative PCA morphine requirements. Can J Anaesth 1996;43(9):900-6.

13. Ogun C, Kirgiz E, Duman A, et al. The comparison of intrathecal isobaric ropivacaine and isobaric ropivacaineclonidine for caesarean delivery. The Internet Journal of Anaesthesiology 2006;15(1)

14. Kallio H, Snall EVT, Tuomas CA, et al. Comparison of hyperbaric and plain ropivacaine $15 \mathrm{mg}$ in spinal anaesthesia for lower limb surgery. $\mathrm{Br} \mathrm{J}$ Anaesth 2004;93(5):664-9.

15. De Kock M, Gautier $\mathrm{P}$, Fanard L, et al. Intrathecal ropivacaine and clonidine for ambulatory knee arthroscopy, a dose response study. Anaesthesiology 2001;94(4):574-8. 